\title{
Phosphoinositides Signaling and Epithelial-to-Mesenchymal Transition: Putative Topic for Basic Toxicological Research
}

\author{
Chang Ho Lee \\ Department of Phamacology and Biomedical Science, College of Medicine, \\ Hanyang University, Seoul 133-791, Korea
}

Received January 30, 2008; Accepted February 19, 2008

\begin{abstract}
$\operatorname{Ptdlns}(4,5) \mathrm{P}_{2}$ is a key cellular phosphoinositide that localizes in separate and distinctive pools in subcellular membrane and vesicular compartments. In membranes, $\operatorname{Ptdlns}(4,5) \mathrm{P}_{2}$ acts as a precursor to second messengers and is itself a main signaling and targeting molecule. Specific subcellular localization of type I PIP kinases directed by interacting with specific targeting module differentiates Ptdins $(4,5) \mathrm{P}_{2}$ production in a spatial and temporal manner. Several lines of evidences support the idea that $P$ tdlns $(4,5) P_{2}$ is generated in very specific pools in a spatial and temporal manner or by feeding Ptdlns $(4,5) \mathrm{P}_{2}$ directly to effectors. In this concept, the interaction of PIPKI isoforms with a specific targeting module to allow precise subcellular targeting modulates highly specific Ptdlns $(4,5) P_{2}$ synthesis and channeling overall effectors. For instance, localization of PIPKly661 to focal adhesions by an interaction with talin results in spatial and temporal production of Ptdlns $(4,5) \mathrm{P}_{2}$, which regulates EGF-stimulated directional cell migration. In addition, Type $1 \gamma$ PIPK is targeted to E-cadherin in cell adherence junction and plays a role in controlling dynamics of cell adherence junction and endocytosis of E-cadherin. Characterizing how PIP kinase isoforms are regulated by interactions with their targeting modules, as well as the mechanisms by which their product, Ptdlns $(4,5) P_{2}$, exerts its effects on cellular signaling processes, is crucial to understand the harmonized control of numerous cellular signaling pathways. Thus, in this review the roles of the $\operatorname{Ptdlns}(4) P(5)$ kinases and $P \operatorname{tdlns}(4,5) \mathrm{P}_{2}$ were described and critically reviewed in terms of regulation of the E-cadherin trafficking, cell migration, and formation of cell adherence junction which is indispensable and is tightly controlled in epithelial-to-mesenchymal transition process.
\end{abstract}

Key words: PIP kinases, PIPKIy661, E-cadherin, EMT, Adherence Junction.

Phosphoinositide messengers and PIP kinases. It is well known that $\mathrm{Ptdlns}(4,5) \mathrm{P}_{2}$ is a major cellular phosphoinositide that exists in discrete and compartmentalized pools in subcellular membrane and vesicular structures. In membranes, Ptdlns $(4,5) \mathrm{P}_{2}$ acts as a precursor to second messengers and is itself a key signaling and targeting molecule (Niggli, 2005). Distinct Ptdlns $(4,5) \mathrm{P}_{2}$ pools are involved in modulating a number of cellular activities such as cell motility (Golub and Caroni, 2005; Insall and Weiner, 2001; Kisseleva et al., 2005), gating of ion channels (Hilgemann and Ball, 1996; Suh and Hille, 2005), exocytosis (Aikawa and Martin, 2003; Aoyagi et al., 2005; Gong et al., 2005) and vesicular trafficking (Downes et al., 2005; Martin,

Correspondence to: Chang Ho Lee, Department of Pharmacology, College of Medicine, Hanyang University, Sungdonggu, Seoul 133-791, Korea

E-mail: jennysue@hanyang.ac.kr
2001).

PIP kinase family are classified into two subtypes (type I and II), which act to produce Ptdlns $(4,5) \mathrm{P}_{2}$ from distinctive substrate pools. Type I PIP kinases (PIPKI) utilize Ptdlns(4)P as a substrate (Rameh et al., 1997), while Type II PIP kinases (PIPKII) utilize Ptdlns(5)P (Rameh et al., 1997; Zhang et al., 1997). PIPKs also use Ptdlns3P as a substrate, with lower in vitro efficacy, and, interestingly, produce $\operatorname{Ptd} \operatorname{lns}(3,4,5) \mathrm{P}_{3}$ by a concerted double phosphorylation mechanism (Zhang et al., 1997). The role of Ptdlns3P as substrate for production of Ptdins $(3,4,5) P_{3}$ by PIPK in vivo has not yet been characterized. The type I and II PIP kinase subfamilies consist of three major isoforms, $\alpha, \beta$, and $\gamma$, and these isoforms themselves have a number of splice variants (Boronenkov et al., 1998; Ishihara et al., 1996, 1998; Itoh et al., 1998; Loijens and Anderson, 1996). The nomenclature for PIPKI $\alpha$ and PIPKI $\beta$ are switched 
between humans and mice (Ishihara et al., 1998). These PIPK isotypes synthesize Ptdlns $(4,5) \mathrm{P}_{2}$ in diverse subcellular locations and are key regulators of $\operatorname{Ptd} \operatorname{lns}(4,5) \mathrm{P}_{2^{-}}$ mediated cellular signaling events. Distinct substrate specificity of PIPK isotypes are determined by the activation loop. The activation loops of types I and II PIP kinases differ critically in only one amino acid residue, a glutamate (type l's) or an alanine (type II's), indicating that the substrate binding pocket has a high degree of specificity (Kunz et al., 2000). Substrate specificity given by the distinctive activation loop of PIP kinase subfamilies allocate for non-redundant physiological pathways to regulate subcellular Ptdlns $(4,5) \mathrm{P}_{2}$ levels.

Specific localization of type I PIP kinases by interacting with unique targeting module defines a spatial and temporal production of Ptdlns $(4,5) \mathrm{P}_{2}$ in distinct subcellular compartments (Kunz et al., 2000). Several lines of evidences suggest that spatial and temporal production of Ptdlns $(4,5) P_{2}$ is a key process for regulating a number of distinct subcellular events. Each members of the PIP kinases subfamilies have been shown to be downstream effectors in small G-protein signaling cascades and in many cases produce cellular Ptdlns $(4,5) \mathrm{P}_{2}$ under control of specific small G-protein signaling units (Doughman et al., 2003; Oude Weernink et al., 2004). Functional interaction of small G-proteins and PIP kinases makes it possible to utilize subcellular phosphoinositide turnover for coordinated organization of the cellular signaling machinery. For instance, the Rho and Arf families of monomeric G-proteins translocate and regulate activities of each members of PIP kinase subfamilies, thereby coordinating production and availability of Ptdlns $(4,5) \mathrm{P}_{2}$ at specific subcellular compartments in the cell. These activities are critical for appropriate regulation of actin dynamics and cytoskeletal-dependent functions of the cell (Honda et al., 1999; Yang et al., 2004). Additionally, the spatial and temporal synthesis of Ptdlns $(4,5) \mathrm{P}_{2}$ by PIP kinases is also regulated by a complex regulatory feedback loop involving phospholipase $\mathrm{D}$ and its reaction product, phosphatidic acid (Divecha et al., 2000; Jenkins et al., 1994; Jones et al., 2000; Powner et al., 2005; Powner and Wakelam, 2002; Yang et al., 2004).

Several lines of evidences support the idea that Ptdlns $(4,5) P_{2}$ is generated in highly specific pools in a spatial and temporal manner or by feeding Ptdlns $(4,5) P_{2}$ directly to effectors (Ling et al., 2002, 2006, 2007). In this concept, the interaction of PIPKI isoforms with a specific targeting module to allow precise subcellular targeting modulates highly specific $\operatorname{Ptdlns}(4,5) \mathrm{P}_{2}$ synthesis and channeling overall effectors. For instance, localization of PIPKly661 to focal adhesions by an interaction with talin results in spatial and temporal production of Ptdlns $(4,5) \mathrm{P}_{2}$, which regulates EGF-stimulated directional cell migration (Sun et al., 2007), as well as strengthens the binding of talin to $\beta$-integrin (Ling et al., 2002). In addition, Type I $\gamma$ PIPK is targeted to E-cadherin in cell adherence junction and plays a role in controlling dynamics of cell adherence junction and endocytosis of E-cadherin (Ling et al., 2007).

Characterizing how PIP Kinases are regulated by interactions with their targeting modules, as well as the mechanisms by which their product, Ptdlns $(4,5) P_{2}$, exerts its effects on cellular signaling processes, is critical to understand the harmonized control of numerous cellular signaling pathways. Thus, in this review the roles of the $P \operatorname{td} \ln s(4) P(5)$ kinases and $P \operatorname{td} \ln s(4,5) P_{2}$ were described and critically reviewed in terms of regulation of the E-cadherin trafficking, cell migration, and formation of cell adherence junction which is indispensable and is tightly controlled in EMT process.

Definition of EMT. The epithelial-to-mesenchymal transition (EMT) is a cellular process characterized by a loss of the polarized epithelial phenotype with a transition to a mesenchymal or more migratory phenotype. EMT is a normal biological process essential for cell movement and generation of new tissue types during embryonic development. It is a reversible process that occurs when cells lose a polarity and the cell-cell contacts which are formed via adherence junctions, migrate to different subcellular locations, and then revert to their original phenotype via mesenchymal-to-epithelial transition (MET). EMT, if it is deregulated, also plays a role in the pathogenic process such as cancer metastasis and tissue fibrosis (Arias, 2001; Hugo et al., 2007; Moustakas and Heldin, 2007; Thiery, 2002).

Cadherins, adherence junction, and cell polarity. Adherence junction, tight junction, and desmosomes support adhesion between neighboring epithelial cells, initiate the assembly of the mechanical cytoskeletal linkage, and facilitate the formation of a polarized epithelial monolayers (Gumbiner, 1996). These junctions allow the separation of apical and basolateral membrane domains that vary in protein and lipid content, and the resultant polarity will be crucial to normal cell function. (Wodarz and Nathke, 2007). In epithelia, adherence junction formation is mediated by homophilic binding of E-cadherin molecules on neighboring cells, which is a calcium-dependent process (Gumbiner, 1996). These interactions connect adjacent cells and promote the assembly of cadherin complex consisting of p120-, $\beta-$, and $\alpha$-catenins, which links E-cadherin complex to the 
actin cytoskeleton. The E-cadherin-mediated cell adherence junction is thought to serve as an initial cue for the development of apical-basolateral cell polarity (Theard et al., 2007; Vega-Salas et al., 1987).

There exists a diverse family of cadherin proteins. The expression of different cadherin isoforms during various stages of tissue development promotes proper cell proliferation and differentiation and provides cues for the maintenance of tissue and organ integrity (Carvell et al., 2007; Syed et al., 2007; Vestweber, 2007). Cadherins maintain adhesive junctions between epithelial, vascular endothelial, and cardiac myocytes (Halbleib and Nelson, 2006; Vestweber, 2007; Zuppinger et al., 2000). One specific cadherin isoform, Ecadherin, plays a key role in cellular organization during embryogenesis and organogenesis as well as in morphogenesis and wound healing in mature organ (Halbleib and Nelson, 2006). N-cadherin and VE-cadherin modulate cardiac morphology and vascular genesis, respectively (Vestweber, 2007; Zuppinger et al., 2000).

EMT signals. Several soluble factors, such as epidermal growth factor (EGF), hepatocyte growth factor (HGF), fibroblast growth factor (FGF), and transforming growth factor (TGF $\beta$ ) induce EMT in vivo (Radisky, 2005; Thiery, 2002; Willis and Borok, 2007; Zavadil and Bottinger, 2005). In vitro, however, these signals are not function-specific and can trigger both EMT and proliferation. EMT is a characteristic feature of cells undergoing proliferation (Arias, 2001; Birchmeier and Birchmeier, 1995; Thiery, 2002; Vernon and LaBonne, 2004). While several signal transduction pathways have been implicated in the regulation of EMT, it is not fully clear as to how this process is initiated and perpetuated.

Diverse cellular signaling events mediated by, in particular, the PI3-kinase, monomeric G-protein Rac and Ras, and protein tyrosine kinases, Fak and Src pathways, can also initiate and modulate EMT (Frame et al., 2002; Savagner, 2001; Van Aelst and Symons, 2002). However, these pathways must first disrupt direct cadherin-cadherin cell contacts in adherence junctions. These junctions assemble in sequential steps initiated by a lateral dimerization and homophilic binding of $E$ cadherin between cells, resulting in weak cell-cell adhesion (Anastasiadis and Reynolds, 2000; Conacci-Sorrell et al., 2002; Jamora and Fuchs, 2002; Knust, 2000). In addition, formation of a complex of cytosolic proteins, including catenins and actin binding proteins such as $\alpha$-actinin is required to mediate a linkage to the actin cytoskeleton, which strengthens cell-cell contacts. In epithelial cells, the configuration of strong cell adhesion complexes is controlled by various signaling pathways involving not only those mentioned above, but also the mitogen activated protein kinase (MAP kinase) signaling pathway and transcriptional regulation mediated by Snail and Slug transcription factor (Arias, 2001; Birchmeier and Birchmeier, 1995; Cano et al., 2000; Frame et al., 2002; Frisch, 1997; Savagner, 2001; Thiery, 2002; Van Aelst and Symons, 2002). Ras-MAP kinase signaling axis can activate two related transcription factor Snail and Slug which are transcriptional repressors of E-cadherin and consequently, expression of Snail and Slug induce a loss of cadherin-mediated intercellular adhesion that is a prerequisite for EMT (Becker et al., 2007; Hajra et al., 2002).

A characteristic feature of the EMT can be observed in epithelial cell-derived cancers, such as ovarian, breast, colon, and prostate cancers. More than sixty percent of all cancers are derived from epithelial cells (Hanahan and Weinberg, 2000). The loss of E-cadherin-mediated cell-cell contacts in epithelial cells leads to a loss of polarization and is a key indicator of transition from the epithelial to the mesenchymal phenotype (Arias, 2001; Birchmeier and Birchmeier, 1995; Frame et al., 2002; Frisch, 1997; Hanahan and Weinberg, 2000; Savagner, 2001; Thiery, 2002; Van Aelst and Symons, 2002). Clinically, the loss of cell surface E-cadherin and the gain of $\mathrm{N}$-cadherin is a convincing marker of tumor metastasis as well as poor patient prognosis. During tumor progression, the expression of E-cadherin is suppressed or inactivated by Snail or Slug-dependent transcriptional mechanisms (Nelson and Nusse, 2004). In addition, control of E-cadherin turnover can modulate its role in adherence junction. For instance, the loss of E-cadherin from cell adherence junctions is initiated by tumor promoting EMT signaling pathways involving Src, Ras, and growth factors (Birchmeier and Birchmeier, 1995; Frame et al., 2002; Frisch, 1997; Hanahan and Weinberg, 2000; Savagner, 2001; Thiery, 2002; Van Aelst and Symons, 2002).

Cellular interaction with extracellular matrix components also influences on EMT processes. In particular, there are roles for integrin signaling in EMT, specifically involving $\beta 1$ and $\beta 3$ integrins. Integrins are heterodimeric extracellular matrix (ECM) receptors. These receptors consist of one $\alpha$ - and one $\beta$-integrin subunit and mediate epithelial cell binding to the ECM through focal adhesion, leading to diverse cell signaling cascades that regulate cell migration, proliferation, cell survival and cellular phenotype (Hynes, 2002). Integrin-linked kinase (ILK) mediates integrin signaling triggered by extracellular matrix molecules and other growth factors by interacting with the cytoplasmic domain of $\beta 1$ and $\beta 3$ 
integrin subunits (Oloumi et al., 2004). Activation of ILK in epithelial cells results in disruption of cell-extracellular matrix and intercellular adhesions through down-regulation of E-cadherin expression, and nuclear buildup of $\beta$-catenin, suggesting that changing integrin signaling can modulate the strength of intercellular adhesions, and thus controlling EMT process (Oloumi et al., 2004).

PIP kinase regulation of cell migration, E-cadherin trafficking, and EMT. Several lines of evidences suggest a role of PIP Kinase in EMT via the spatial and temporal generation of $\operatorname{Ptdlns}(4,5) P_{2}$ since cell migration and the modulation of adherence junction and E-cadherin trafficking are modulated by $\operatorname{Ptdlns}(4,5) \mathrm{P}_{2^{-}}$ dependent mechanisms (Ling et al., 2002, 2006, 2007; Sun et al., 2007). Cell migration requires the highly coordinated processes including focal adhesion formation and turnover as well as dynamic changes in cytoskeletal rearrangements (Horwitz and Parsons, 1999; Webb et al., 2002). The sequential phases of cell movement include extension of a protrusion at the leading edge of the cell, formation of stable attachments near the leading edge of the protrusion, and then release of attachment and retraction at the trailing edge of the cells, thus providing driving force for cell movement (Webb et al., 2002). Actin polymerization dynamics is a well-established underlining mechanism in the formation of leading edge protrusion (DesMarais et al., 2005). Many observations indicate that $\operatorname{Ptdlns}(4,5) \mathrm{P}_{2}$ is a key signaling molecule in the regulation of the assembly of the cell migratory machinery. Ptdlns $(4,5) \mathrm{P}_{2}$ regulates dynamics of the actin rearrangement by interacting with diverse actin binding proteins such as $\alpha$-actinin, WASP/ N-WASP, gelsolin, cofilin, and villin (Fawcett and Pawson, 2000; Lanier and Gertler, 2000; Ling et al., 2006; Niggli, 2005). Ptdlns $(4,5) \mathrm{P}_{2}$ has also been proposed to regulate the dynamics of focal adhesion assembly by interacting with talin, vinculin, ezrin/radixin/moesin, calpain, and other proteins involved in focal adhesion formation (Ling et al., 2006; Niggli, 2005). In addition, microtubules facilitate cell migration by being captured and stabilized at the leading edge (Golub and Caroni, 2005) and by triggering the disassembly of focal adhesions (Tilghman et al., 2005). Actin-myosin contractility is involved for retracting rear edge of the cells (Yam et al., 2007).

The other critical modulators of actin rearrangement are the monomeric G-proteins Rac, Cdc42, Rho, and Arf (Hall, 1998; Moss and Vaughan, 1998; Nobes and Hall, 1995; Ridley and Hall, 1992; Ridley et al., 1992; Symons, 1995, 1996; Van Aelst and D'Souza-Schorey, 1997; Zigmond, 1996). These small G-proteins modu- late the actin cytoskeleton in membrane ruffle assembly, the assembly of filopodia, lamellipodia, actin stress fibers, and focal adhesions. Phosphoinositide signaling molecule, such as $\operatorname{Ptdlns}(4,5) \mathrm{P}_{2}$, regulate the activities of these small G-protins in direct and indirect ways (Brown et al., 1998; Donaldson and Jackson, 2000; Kam et al., 2000; Parker, 1995). For example, membrane ruffling requires harmonization between PIPKIa and Rac signaling processes. Rac1 has been shown to be associated with PIPKI $\alpha$, forming a Rac1-PIPKI $\alpha$ signaling complex on the membrane and in the cytosol (Doughman et al., 2003; Tolias et al., 1998). In this complex, membrane-associated Rac activates PIPKIa to produce a localized $\operatorname{Ptdlns}(4,5) \mathrm{P}_{2}$. Platelet-derived growth factor (PDGF)-induced membrane ruffle formation is augmented dramatically by increasing ratios of active Rac to PIPKI $\alpha$ in MG63 cells, indicating that the localized association of PIPKl $\alpha$ with Rac in membrane and the signaling events of activated Rac are crucial in localized actin remodeling to form cell membrane ruffles (Doughman et al., 2003).

As an extension of these observations, the role of specific PIP kinases in the regulation of cell migration is now partly being clarified. There are several alternatively spliced variants of PIPKl $\gamma$ in cells. Among them, two major variants, PIPKIy635 and PIPKIy661, which differ by a 26-amino acid C-terminal extension (Ishihara et al., 1998). The 26-amino acid C-terminal extension binds to talin and targets PIPKIy661, but not PIPKI $\gamma 635$, to focal adhesions (Di Paolo et al., 2002; Ling et al., 2002). These specific translocation of PIPKly661 allows for the generation of Ptdlns $(4,5) P_{2}$ at focal adhesion in a spatial and temporal manner, which is identified to enhance the local association between integrin and talin (Martel et al., 2001). Talin is one of cytoskeletal proteins involved in connecting the integrin family of cell adhesion molecule with the actin cytoskeleton in focal adhesion. The interaction of talin to $\beta$-integrin enhances the affinity of integrin for its ligands and activates the integrin heterodimers (Tadokoro et al., 2003). PIPKly661 targeted to adhesions may modulate the integrin signaling and the adhesion formation through modulation by focal adhesion kinase, Src, and talin (Ling et al., 2002, 2003). These data suggest that PIPKly661 plays critical roles in modulating focal adhesion dynamics for cell migration.

Contrary to a robust accumulation of $\operatorname{Ptdlns}(3,4,5) \mathrm{P}_{3}$ at the leading edge of migrating cells in response to a shallow gradient of external chemoattractant (Charest and Firtel, 2006; Janetopoulos et al., 2004; Wang et al., 2002), overall levels of cellular $P \operatorname{tdlns}(4,5) P_{2}$ are relatively high and undergo only modest changes upon 
cell migration (Ling et al., 2006). Nevertheless, local Ptdlns $(4,5) \mathrm{P}_{2}$ production is tightly regulated, both spatially and temporally, to execute the rapid adhesion turnover and cytoskeletal rearrangement in the leading edge of migrating cell. For example, local EGF stimulation induces a rapid co-translocation of PIPKIy661 and talin to the leading edge and assembly into nascent adhesion (Sun et al., 2007).

Integral membrane proteins such as E-cadherin are transported to and from the plasma membrane in lipid vesicles (Brett et al., 2002; Cremona and De Camilli, 2001; Kirchhausen, 1999; Martin, 2001; Takei and Haucke, 2001). Strict regulation of vesicular trafficking pathway controls the amount of E-cadherin residing on the plasma membrane and is essential for modulating E-cadherin functions and adherence junction assembly (Bryant and Stow, 2004). In mammalian cells, trafficking and assembly of E-cadherin is controlled by diverse signaling events which include small G-proteins Rab and Arf6, p120-catenin, tyrosine phosphorylation, and ubiquitination (D'Souza-Schorey, 2005). Transportation of E-cadherin is controlled by the composition of cadherin complex as well as the vesicular trafficking machinery composed of multiple adaptor and signaling proteins (D'Souza-Schorey, 2005). Several lines of evidence suggest that endocytic E-cadherin trafficking is mediated by both clathrin dependent- and independent pathways (Le et al., 1999). Both of these pathways depend on phosphoinositide signaling molecule, particularly, Ptdlns $(4,5) \mathrm{P}_{2}$. Endocytosis of E-cadherin requires clathrin lattice assembly and is controlled by a family of adaptors known as the clathrin adaptor-protein (AP) complex (Kirchhausen, 1999). AP complexes, such as AP-1, AP-2, AP-3, and AP-4 are important for recognizing signals for sorting of transmembrane proteins to endosomes and lysosomes. These AP complexes consist of several distinct proteins subunits which mediate endocytosis and sorting in epithelial cells (Gan et al., 2002). Of these subunits, the $\mu$ subunit of AP complex contains the binding site for tyrosine- or dileucine-based cargo sorting motif (Bonifacino and Traub, 2003). Interaction of the $\mu$ subunit of AP-1B/AP-2 complexes with tyrosine sorting motif of cargo proteins is $\operatorname{Ptdlns}(4,5) \mathrm{P}_{2^{-}}$ dependent process, which is crucial for membrane trafficking and endocytosis (Cremona and De Camilli, 2001; Honing et al., 2005; Martin, 2001).

Local level of phosphoinositides is controlled by specific lipid kinases and phosphatases. However, the precise mechanism by which $\operatorname{Ptdlns}(4,5) \mathrm{P}_{2}$ production is regulated to control these trafficking events has not been elucidated. Recent data demonstrate that spatial and temporal targeting of type I PIP kinases (PIPKIs) is a crucial mechanism for $\operatorname{Ptdlns}(4,5) \mathrm{P}_{2}$ generation in controlling membrane trafficking and formation of adherence junction (Ling et al., 2007). In MDCK canine epithelial cells, PIPKly661 co-localizes with the E-cadherin dimers through spatial and temporal targeting to cell adherence junctions. The translocated PIPKly661 modulates E-cadherin trafficking and adherence junction formation by localized production of $\operatorname{Ptd} \operatorname{lns}(4,5) \mathrm{P}_{2}$. PIPKly661 is now postulated to act as a scaffold molecule which combines E-cadherin and AP complexes together (Ling et al., 2007).

Conclusion and perspective. The current concept suggests that PIP kinases are translocated to specific subcellular compartments in spatial and temporal manner by interaction with specific targeting module, resulting in targeted production of Ptdlns $(4,5) \mathrm{P}_{2}$ and modulation of site-specific function (Santarius et al., 2006). Thus, PIPKly661 targeting to focal adhesions by an association with talin results in spatially generated $\operatorname{Ptd} \operatorname{lns}(4,5) \mathrm{P}_{2}$, which regulates EGF-stimulated directional cell migration. In addition, a spatial targeting of PIPKly661 to Ecadherin dimers in cell adherence junction suggests a significant role of PIPKly661 in controlling dynamics of cell adherence junction and E-cadherin endocytosis, which is necessary and crucial in modulation of EMT process (Fig. 1). Cell stress caused by diverse toxicants can induce alterations in well established EMTrelated cell signaling pathways such as changes in the expression of transcription factor Snail and related target genes. Moreover, it is conceivable that toxicants may influence on phosphoinositide signaling pathways or the targeting factors for PIPKly661 translocation to focal adhesion or cell adherence junctions (Fig. 1). Col-

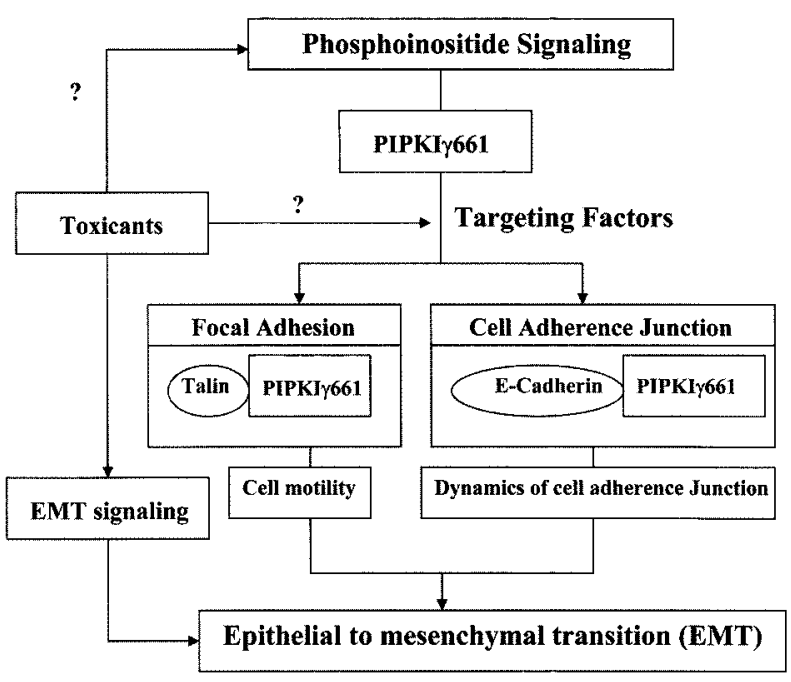

Fig. 1. Phosphoinositide signaling and EMT. 
lectively, current review will provide us putative topics for investigating novel modes of action of EMT-inducing toxicants in terms of phosphoinositide signaling pathways.

\section{ACKNOWLEDGEMENT}

This work was supported by Korea Science and Engineering Foundation grant RO1-2005-000-10596-0 funded by the Korean government

\section{REFERENCES}

Aikawa, Y. and Martin, T.F. (2003). ARF6 regulates a plasma membrane pool of phosphatidylinositol(4,5)bisphosphate required for regulated exocytosis. J. Cell Biol., 162, 647659.

Anastasiadis, P.Z. and Reynolds, A.B. (2000). The $p 120$ catenin family: complex roles in adhesion, signaling and cancer. J. Cell Sci., 113, 1319-1334.

Aoyagi, K., Sugaya, T., Umeda, M., Yamamoto, S., Terakawa, S. and Takahashi, M. (2005). The activation of exocytotic sites by the formation of phosphatidylinositol 4,5-bisphosphate microdomains at syntaxin clusters. J. Biol. Chem., 280, 17346-17352.

Arias, A.M. (2001). Epithelial mesenchymal interactions in cancer and development. Cell, 105, 425-431.

Becker, K.F., Rosivatz, E., Blechschmidt, K., Kremmer, E., Sarbia, M. and Hofler, H. (2007). Analysis of the E-cadherin repressor Snail in primary human cancers. Cells Tissues Organs, 185, 204-212.

Birchmeier, W. and Birchmeier, C. (1995). Epithelial-mesenchymal transitions in development and tumor progression. EXS, 74, 1-15.

Bonifacino, J.S. and Traub, L.M. (2003). Signals for sorting of transmembrane proteins to endosomes and lysosomes. Annu. Rev. Biochem., 72, 395-447.

Boronenkov, I.V., Loijens, J.C., Umeda, M. and Anderson, R.A. (1998). Phosphoinositide signaling pathways in nuclei are associated with nuclear speckles containing pre-mRNA processing factors. Mol. Biol. Cell., 9, 3547-3560.

Brett, T.J., Traub, L.M. and Fremont, D.H. (2002). Accessory protein recruitment motifs in clathrin-mediated endocytosis. Structure, 10, 797-809.

Brown, M.T., Andrade, J., Radhakrishna, H., Donaldson, J.G., Cooper, J.A. and Randazzo, P.A. (1998). ASAP1, a phospholipid-dependent arf GTPase-activating protein that associates with and is phosphorylated by Src. Mol. Cell. Biol., 18, 7038-7051.

Bryant, D.M. and Stow, J.L. (2004). The ins and outs of Ecadherin trafficking. Trends Cell Biol., 14, 427-434.

Cano, A., Perez-Moreno, M.A., Rodrigo, I., Locascio, A., Blanco, M.J., del Barrio, M.G., Portillo, F. and Nieto, M.A. (2000). The transcription factor snail controls epithelialmesenchymal transitions by repressing E-cadherin expression. Nat. Cell Biol., 2, 76-83.

Carvell, M.J., Marsh, P.J., Persaud, S.J. and Jones, P.M.
(2007). E-Cadherin interactions regulate beta-cell proliferation in islet-like structures. Cell Physiol. Biochem., 20, 617-626.

Charest, P.G. and Firtel, R.A. (2006). Feedback signaling controls leading-edge formation during chemotaxis. Curr. Opin. Genet. Dev., 16, 339-347.

Conacci-Sorrell, M., Zhurinsky, J. and Ben-Ze'ev, A. (2002). The cadherin-catenin adhesion system in signaling and cancer. J. Clin. Invest., 109, 987-991.

Cremona, O. and De Camilli, P. (2001). Phosphoinositides in membrane traffic at the synapse. J. Cell Sci., 114, 10411052.

D'Souza-Schorey, C. (2005). Disassembling adherens junctions: breaking up is hard to do. Trends Cell Biol., 15, 1926.

DesMarais, V., Ghosh, M., Eddy, R. and Condeelis, J. (2005). Cofilin takes the lead. J. Cell Sci., 118, 19-26.

Di Paolo, G, Pellegrini, L., Letinic, K., Cestra, G., Zoncu, R., Voronov, S., Chang, S., Guo, J., Wenk, M.R. and De Camilli, P. (2002). Recruitment and regulation of phosphatidylinositol phosphate kinase type 1 gamma by the FERM domain of talin. Nature, 420, 85-89.

Divecha, N., Roefs, M., Halstead, J.R., D'Andrea, S., Fernandez-Borga, M., Oomen, L., Saqib, K.M., Wakelam, M.J. and D'Santos, C. (2000). Interaction of the type lalpha PIPkinase with phospholipase D: a role for the local generation of phosphatidylinositol 4,5-bisphosphate in the regulation of PLD2 activity. EMBO J., 19, 5440-5449.

Donaldson, J.G. and Jackson, C.L. (2000). Regulators and effectors of the ARF GTPases. Curr. Opin. Cell Biol., 12, 475-482.

Doughman, R.L., Firestone, A.J., Wojtasiak, M.L., Bunce, M.W. and Anderson, R.A. (2003). Membrane ruffling requires coordination between type lalpha phosphatidylinositol phosphate kinase and Rac signaling. J. Biol. Chem., 278, 23036-23045

Downes, C.P., Gray, A. and Lucocq, J.M. (2005). Probing phosphoinositide functions in signaling and membrane trafficking. Trends Cell Biol., 15, 259-268.

Fawcett, J. and Pawson, T. (2000). Signal transduction. NWASP regulation--the sting in the tail. Science, 290, 725726.

Frame, M.C., Fincham, V.J., Carragher, N.O. and Wyke, J.A. (2002). v-Src's hold over actin and cell adhesions. Nat. Rev. Mol. Cell Biol., 3, 233-245.

Frisch, S.M. (1997). The epithelial cell default-phenotype hypothesis and its implications for cancer. Bioessays, 19, 705-709.

Gan, Y., McGraw, T.E. and Rodriguez-Boulan, E. (2002). The epithelial-specific adaptor AP1B mediates post-endocytic recycling to the basolateral membrane. Nat. Cell Biol., 4, 605-609.

Golub, T. and Caroni, P. (2005). PI(4,5)P2-dependent microdomain assemblies capture microtubules to promote and control leading edge motility. J. Cell Biol., 169, 151-165.

Gong, L.W., Di Paolo, G., Diaz, E., Cestra, G., Diaz, M.E., Lindau, M., De Camilli, P. and Toomre, D. (2005). Phosphatidylinositol phosphate kinase type I gamma regulates dynamics of large dense-core vesicle fusion. Proc. Natl. 
Acad. Sci. USA, 102, 5204-5209

Gumbiner, B.M. (1996). Cell adhesion: the molecular basis of tissue architecture and morphogenesis. Cell, 84, 345-357.

Hajra, K.M., Chen, D.Y. and Fearon, E.R. (2002). The SLUG zinc-finger protein represses $\mathrm{E}$-cadherin in breast cancer. Cancer. Res., 62, 1613-1618.

Halbleib, J.M. and Nelson, W.J. (2006). Cadherins in development: cell adhesion, sorting, and tissue morphogenesis. Genes Dev., 20, 3199-3214.

Hall, A. (1998). Rho GTPases and the actin cytoskeleton. Science, 279, 509-514.

Hanahan, D. and Weinberg, R.A. (2000). The hallmarks of cancer. Cell, 100, 57-70.

Hilgemann, D.W. and Ball, R. (1996). Regulation of cardiac $\mathrm{Na}^{+}, \mathrm{Ca}^{2+}$ exchange and KATP potassium channels by PIP2. Science, 273, 956-959.

Honda, A., Nogami, M., Yokozeki, T., Yamazaki, M., Nakamura, H., Watanabe, H., Kawamoto, K., Nakayama, K., Morris, A.J., Frohman, M.A. and Kanaho, Y. (1999). Phosphatidylinositol 4-phosphate 5-kinase alpha is a downstream effector of the small G protein ARF6 in membrane ruffle formation. Cell, 99, 521-532.

Honing, S., Ricotta, D., Krauss, M., Spate, K., Spolaore, B., Motley, A., Robinson, M., Robinson, C., Haucke, V. and Owen, D.J. (2005). Phosphatidylinositol-(4,5)-bisphosphate regulates sorting signal recognition by the clathrin-associated adaptor complex AP2. Mol. Cell, 18, 519-531.

Horwitz, A.R. and Parsons, J.T. (1999). Cell migration--movin' on. Science, 286, 1102-1103

Hugo, H., Ackland, M.L., Blick, T., Lawrence, M.G., Clements, J.A., Williams, E.D. and Thompson, E.W. (2007) Epithelial--mesenchymal and mesenchymal--epithelial transitions in carcinoma progression. J. Cell Physiol., 213, 374-383.

Hynes, R.O. (2002). Integrins: bidirectional, allosteric signaling machines. Cell, 110, 673-687.

Insall, R.H. and Weiner, O.D. (2001). PIP3, PIP2, and cell movement--similar messages, different meanings? Dev. Cell, 1, 743-747.

Ishihara, H., Shibasaki, Y., Kizuki, N., Katagiri, H., Yazaki, Y., Asano, T. and Oka, Y. (1996). Cloning of cDNAs encoding two isoforms of 68-kDa type I phosphatidylinositol-4phosphate 5-kinase. J. Biol. Chem., 271, 23611-23614.

Ishihara, H., Shibasaki, Y., Kizuki, N., Wada, T., Yazaki, Y., Asano, T. and Oka, Y. (1998). Type I phosphatidylinositol4-phosphate 5-kinases. Cloning of the third isoform and deletion/substitution analysis of members of this novel lipid kinase family. J. Biol. Chem., 273, 8741-8748.

Itoh, T., ljuin, T. and Takenawa, T. (1998). A novel phosphatidylinositol-5-phosphate 4-kinase (phosphatidylinositol-phosphate kinase llgamma) is phosphorylated in the endoplasmic reticulum in response to mitogenic signals. J. Biol. Chem., 273, 20292-20299

Jamora, C. and Fuchs, E. (2002). Intercellular adhesion, signalling and the cytoskeleton. Nat. Cell Biol., 4, E101-108.

Janetopoulos, C., Ma, L., Devreotes, P.N. and Iglesias, P.A (2004). Chemoattractant-induced phosphatidylinositol 3,4,5trisphosphate accumulation is spatially amplified and adapts independent of the actin cytoskeleton. Proc. Natl. Acad.
Sci. USA, 101, 8951-8956

Jenkins, G.H., Fisette, P.L. and Anderson, R.A. (1994). Type I phosphatidylinositol 4-phosphate 5-kinase isoforms are specifically stimulated by phosphatidic acid. J. Biol. Chem., 269, 11547-11554.

Jones, D.R., Sanjuan, M.A. and Merida, I. (2000). Type lalpha phosphatidylinositol 4-phosphate 5-kinase is a putative target for increased intracellular phosphatidic acid. FEBS Lett., 476, 160-165

Kam, J.L., Miura, K., Jackson, T.R., Gruschus, J., Roller, P., Stauffer, S., Clark, J., Aneja, R. and Randazzo, P.A. (2000). Phosphoinositide-dependent activation of the ADP-ribosylation factor GTPase-activating protein ASAP1. Evidence for the pleckstrin homology domain functioning as an allosteric site. J. Biol. Chem., 275, 9653-9663.

Kirchhausen, T. (1999). Adaptors for clathrin-mediated traffic. Annu. Rev. Cell Dev. Biol., 15, 705-732.

Kisseleva, M., Feng, Y., Ward, M., Song, C., Anderson, R.A. and Longmore, G.D. (2005). The LIM protein Ajuba regulates phosphatidylinositol 4,5-bisphosphate levels in migrating cells through an interaction with and activation of PIPKI alpha. Mol. Cell Biol., 25, 3956-3966.

Knust, E. (2000). Control of epithelial cell shape and polarity. Curr. Opin. Genet. Dev., 10, 471-475.

Kunz, J., Wilson, M.P., Kisseleva, M., Hurley, J.H., Majerus, P.W. and Anderson, R.A. (2000). The activation loop of phosphatidylinositol phosphate kinases determines signaling specificity. Mol. Cell, 5, 1-11.

Lanier, L.M. and Gertler, F.B. (2000). Actin cytoskeleton: thinking globally, actin' locally. Curr. Biol., 10, R655-R657.

Le, T.L., Yap, A.S. and Stow, J.L. (1999). Recycling of E-cadherin: a potential mechanism for regulating cadherin dynamics. J. Cell Biol., 146, 219-232.

Ling, K., Bairstow, S.F., Carbonara, C., Turbin, D.A., Huntsman, D.G. and Anderson, R.A. (2007). Type Igamma phosphatidylinositol phosphate kinase modulates adherens junction and $E$-cadherin trafficking via a direct interaction with mu 1B adaptin. J. Cell Biol., 176, 343-353.

Ling, K., Doughman, R.L., Firestone, A.J., Bunce, M.W. and Anderson, R.A. (2002). Type I gamma phosphatidylinositol phosphate kinase targets and regulates focal adhesions. Nature, 420, 89-93.

Ling, K., Doughman, R.L., lyer, V.V., Firestone, A.J., Bairstow, S.F., Mosher, D.F., Schaller, M.D. and Anderson, R.A. (2003). Tyrosine phosphorylation of type Igamma phosphatidylinositol phosphate kinase by Src regulates an integrin-talin switch. J. Cell Biol., 163, 1339-1349.

Ling, K., Schill, N.J., Wagoner, M.P., Sun, Y. and Anderson, R.A. (2006). Movin' on up: the role of Ptdlns $(4,5) P(2)$ in cell migration. Trends Cell Biol., 16, 276-284.

Loijens, J.C. and Anderson, R.A. (1996). Type I phosphatidylinositol-4-phosphate 5-kinases are distinct members of this novel lipid kinase family. J. Biol. Chem., 271, 3293732943.

Martel, V., Racaud-Sultan, C., Dupe, S., Marie, C., Paulhe, F., Galmiche, A., Block, M.R. and Albiges-Rizo, C. (2001). Conformation, localization, and integrin binding of talin depend on its interaction with phosphoinositides. J. Biol. Chem., 276, 21217-21227. 
Martin, T.F. (2001). $\mathrm{Pl}(4,5) \mathrm{P}(2)$ regulation of surface membrane traffic. Curr. Opin. Cell Biol., 13, 493-499.

Moss, J. and Vaughan, M. (1998). Molecules in the ARF orbit. J. Biol. Chem., 273, 21431-21434.

Moustakas, A. and Heldin, C.H. (2007). Signaling networks guiding epithelial-mesenchymal transitions during embryogenesis and cancer progression. Cancer. Sci., 98, 15121520.

Nelson, W.J. and Nusse, R. (2004). Convergence of Wnt, beta-catenin, and cadherin pathways. Science, 303, 14831487.

Niggli, V. (2005). Regulation of protein activities by phosphoinositide phosphates. Annu. Rev. Cell Dev. Biol., 21, 5779 .

Nobes, C.D. and Hall, A. (1995). Rho, rac, and cdc42 GTPases regulate the assembly of multimolecular focal complexes associated with actin stress fibers, lamellipodia, and filopodia. Cell, 81, 53-62.

Oloumi, A., McPhee, T. and Dedhar, S. (2004). Regulation of E-cadherin expression and beta-catenin/Tcf transcriptional activity by the integrin-linked kinase. Biochim. Biophys. Acta., 1691, 1-15

Oude Weernink, P.A., Schmidt, M. and Jakobs, K.H. (2004). Regulation and cellular roles of phosphoinositide 5kinases. Eur. J. Pharmacol., 500, 87-99.

Parker, P.J. (1995). Intracellular signalling. PI 3-kinase puts GTP on the Rac. Curr. Biol., 5, 577-579.

Powner, D.J., Payne, R.M., Pettitt, T.R., Giudici, M.L., Irvine, R.F. and Wakelam, M.J. (2005). Phospholipase D2 stimulates integrin-mediated adhesion via phosphatidylinositol 4-phosphate 5-kinase Igamma b. J. Cell Sci., 118, 29752986.

Powner, D.J. and Wakelam, M.J. (2002). The regulation of phospholipase $\mathrm{D}$ by inositol phospholipids and small GTPases. FEBS Lett., 531, 62-64.

Radisky, D.C. (2005). Epithelial-mesenchymal transition. J. Cell Sci. 118, 4325-4326.

Rameh, L.E., Tolias, K.F., Duckworth, B.C. and Cantley, L.C. (1997). A new pathway for synthesis of phosphatidylinositol-4,5-bisphosphate. Nature, 390, 192-196.

Ridley, A.J. and Hall, A. (1992). The small GTP-binding protein rho regulates the assembly of focal adhesions and actin stress fibers in response to growth factors. Cell, $\mathbf{7 0}$, 389-399.

Ridley, A.J., Paterson, H.F., Johnston, C.L., Diekmann, D. and Hall, A. (1992). The small GTP-binding protein rac regulates growth factor-induced membrane ruffing. Cell, 70, 401-410.

Santarius, M., Lee, C.H. and Anderson, R.A. (2006). Supervised membrane swimming: small G-protein lifeguards regulate PIPK signalling and monitor intracellular Ptdlns $(4,5) \mathrm{P}_{2}$ pools. Biochem. J., 398, 1-13.

Savagner, P. (2001). Leaving the neighborhood: molecular mechanisms involved during epithelial-mesenchymal transition. Bioessays, 23, 912-923.

Suh, B.C. and Hille, B. (2005). Regulation of ion channels by phosphatidylinositol 4,5-bisphosphate. Curr. Opin. Neurobiol., 15, 370-378.

Sun, Y., Ling, K., Wagoner, M.P. and Anderson, R.A. (2007).
Type I gamma phosphatidylinositol phosphate kinase is required for EGF-stimulated directional cell migration. $J$. Cell Biol., 178, 297-308.

Syed, V., Mak, P., Du, C. and Balaji, K.C. (2007). beta-catenin mediates alteration in cell proliferation, motility and invasion of prostate cancer cells by differential expression of E-cadherin and protein kinase D1. J. Cell Biochem., On-line.

Symons, M. (1995). The Rac and Rho pathways as a source of drug targets for Ras-mediated malignancies. Curr. Opin. Biotechnol., 6, 668-674.

Symons, M. (1996), Rho family GTPases: the cytoskeleton and beyond. Trends Biochem. Sci., 21, 178-181.

Tadokoro, S., Shattil, S.J., Eto, K., Tai, V., Liddington, R.C., de Pereda, J.M., Ginsberg, M.H. and Calderwood, D.A. (2003): Talin binding to integrin beta tails: a final common step in integrin activation. Science, 302, 103-106.

Takei, K. and Haucke, V. (2001). Clathrin-mediated endocytosis: membrane factors pull the trigger. Trends Cell Biol., 11, 385-391.

Theard, D., Steiner, M., Kalicharan, D., Hoekstra, D. and van ljzendoorn, S.C. (2007). Cell polarity development and protein trafficking in hepatocytes lacking E-cadherin/betacatenin-based adherens junctions. Mol. Biol. Cell, 18, 2313-2321.

Thiery, J.P. (2002). Epithelial-mesenchymal transitions in tumour progression. Nat. Rev. Cancer., 2, 442-454.

Tilghman, R.W., Slack-Davis, J.K., Sergina, N., Martin, K.H., Iwanicki, M., Hershey, E.D., Beggs, H.E., Reichardt, L.F. and Parsons, J.T. (2005). Focal adhesion kinase is required for the spatial organization of the leading edge in migrating cells. J. Cell Sci., 118, 2613-2623.

Tolias, K.F., Couvillon, A.D., Cantley, L.C. and Carpenter, C.L. (1998). Characterization of a Rac1- and RhoGDI-associated lipid kinase signaling complex. Mol. Cell Biol., 18, 762-770.

Van Aelst, L. and D'Souza-Schorey, C. (1997). Rho GTPases and signaling networks. Genes Dev., 11, 2295-2322.

Van Aelst, L. and Symons, M. (2002). Role of Rho family GTPases in epithelial morphogenesis. Genes Dev., 16, 1032-1054.

Vega-Salas, D.E., Salas, P.J., Gundersen, D. and RodriguezBoulan, E. (1987). Formation of the apical pole of epithelial (Madin-Darby canine kidney) cells: polarity of an apical protein is independent of tight junctions while segregation of a basolateral marker requires cell-cell interactions. J. Cell Biol., 104, 905-916.

Vernon, A.E. and LaBonne, C. (2004). Tumor metastasis: a new twist on epithelial-mesenchymal transitions. Curr. Biol., 14, R719-R721

Vestweber, D. (2008). VE-Cadherin. The major endothelial adhesion molecule controlling cellular junctions and blood vessel formation. Arterioscler. Thromb. Vasc. Biol., 28, 223-232.

Wang, F., Herzmark, P., Weiner, O.D., Srinivasan, S., Servant, G. and Bourne, H.R. (2002). Lipid products of PI(3)Ks maintain persistent cell polarity and directed motility in neutrophils. Nat. Cell Biol., 4, 513-518.

Webb, D.J., Parsons, J.T. and Horwitz, A.F. (2002). Adhesion 
assembly, disassembly and turnover in migrating cells -over and over and over again. Nat. Cell Biol., 4, E97E100.

Willis, B.C. and Borok, Z. (2007). TGF-beta-induced EMT: mechanisms and implications for fibrotic lung disease. Am. J. Physiol. Lung Cell Mol. Physiol, 293, L525-L534.

Wodarz, A. and Nathke, I. (2007). Cell polarity in development and cancer. Nat. Cell Biol., 9, 1016-1024.

Yam, P.T., Wilson, C.A., Ji, L., Hebert, B., Barnhart, E.L., Dye, N.A., Wiseman, P.W., Danuser, G. and Theriot, J.A. (2007). Actin-myosin network reorganization breaks symmetry at the cell rear to spontaneously initiate polarized cell motility. J. Cell Biol., 178, 1207-1221.

Yang, S.A., Carpenter, C.L. and Abrams, C.S. (2004). Rho and Rho-kinase mediate thrombin-induced phosphatidylinositol 4-phosphate 5-kinase trafficking in platelets. $J$.
Biol. Chem., 279, 42331-42336.

Zavadil, J. and Bottinger, E.P. (2005). TGF-beta and epithelial-to-mesenchymal transitions. Oncogene, 24, 5764-5774.

Zhang, X., Loijens, J.C., Boronenkov, I.V., Parker, G.J., Norris, F.A., Chen, J., Thum, O., Prestwich, G.D., Majerus, P.W. and Anderson, R.A. (1997). Phosphatidylinositol-4phosphate 5-kinase isozymes catalyze the synthesis of 3phosphate-containing phosphatidylinositol signaling molecules. J. Biol. Chem., 272, 17756-17761.

Zigmond, S.H. (1996). Signal transduction and actin filament organization. Curr. Opin. Cell Biol., 8, 66-73.

Zuppinger, C., Eppenberger-Eberhardt, M. and Eppenberger, H.M. (2000). N-Cadherin: structure, function and importance in the formation of new intercalated disc-like cell contacts in cardiomyocytes. Heart Fail Rev., 5, 251-257. 